\title{
Misturas de Agrotóxicos em Tanque nas Propriedades Agrícolas do BRASIL ${ }^{1}$
}

\author{
Mixtures of Pesticides in Tank, in Brazilian Farms
}

GAZZIERO, D.L.P. ${ }^{2}$

\begin{abstract}
RESUMO - As infestações de plantas daninhas, pragas e doenças, muitas vezes, ocorrem simultaneamente em uma mesma área agrícola. Nesse caso, a alternativa de controle mais econômica e, por isso, mais comumente adotada pelos produtores é a pulverização de mistura de agrotóxicos em tanque. Nesta pesquisa, a fim de subsidiar as discussões técnicas, são descritas e quantificadas as práticas de campo adotadas em relação às misturas em tanque de agrotóxicos em propriedades agrícolas do Brasil. Para isso, foi elaborado um questionário e enviado aos profissionais que lidam cotidianamente com tratamentos fitossanitários em diferentes regiões do País. Constatou-se que 97\% dos entrevistados utilizam misturas em tanque, $95 \%$ das vezes variando de dois a cinco produtos. Na maioria das vezes, utilizam a dose cheia, isto é, as maiores doses constantes nos rótulos dos agrotóxicos. As aplicações de glyphosate em soja $86 \%$ das vezes são realizadas simultaneamente com inseticidas, fungicidas e outros herbicidas. A maioria dos participantes (72\%) afirmou desconhecer ou considera insuficientes as informações sobre misturas, e 99\% deles demonstraram interesse em recebê-las. Considerando que a mistura em tanque de agrotóxicos é prática comum entre os agricultores, mas pode apresentar vantagens e desvantagens, conclui-se que o tema deve ser discutido com urgência entre os órgãos governamentais competentes e os demais segmentos das cadeias produtivas.
\end{abstract}

Palavras-chave: incompatibilidade, herbicidas, fungicidas, inseticidas, pragas.

\begin{abstract}
The weed, pest and disease infestation, often occur simultaneously in a farm. In such a situation, the most economical alternative to control and, therefore, the more commonly adopted by the producers is the pesticide spray mixture in the tank. In this study, field practices adopted by farmers related to mixtures of pesticides in tank in Brazilian farms are described and quantified. To obtain such information, a questionnaire was developed and implemented with the professionals in different regions of the country. It was found that $97 \%$ of respondents use tank mixtures and most of the time 95\% using 2-5 products. Most often using the highest recommended doses. The applications of glyphosate in soybean are carried out simultaneously with insecticides, fungicides and other herbicides, in $86 \%$ of the times. Most respondents (72\%) reported not knowing about the tank mix prectices and 99\% indicated interest in receiving such data. Whereas the tank in pesticide mixture is common practice among farmers and that this practice has its advantages and disadvantages, it is concluded that the issue should be discussed urgently by government agencies and by other segments of the soybean production chain.
\end{abstract}

Keywords: incompatibility, herbicides, fungicides, insecticides, pest.

\section{INTRODUÇÃO}

O Brasil é um dos maiores produtores e exportadores de alimentos do mundo, e o agronegócio representa um dos principais pilares do PIB brasileiro. Contudo, as condições tropicais, a prática da monocultura, a extensão das áreas agrícolas e a agricultura intensiva geram ambientes propícios ao aumento da frequência e da intensidade de problemas

Recebido para publicação em 25.11.2014 e aprovado em 3.12.2014.

2 Embrapa Soja. Londrina-PR, Brasil, <dionisio.gazziero@embrapa.br>. 
fitossanitários, comparativamente a países situados em regiões frias. Por conseguinte, a frequência de uso de agrotóxicos também é maior que a média verificada em países de altas latitudes.

Plantas daninhas, pragas e doenças podem reduzir a produtividade e comprometer a qualidade dos produtos agrícolas. É comum a ocorrência concomitante dessas infestantes no campo, ao mesmo tempo e na mesma área. Por outro lado, os agrotóxicos não têm espectro de ação capaz de controlar o conjunto de problemas, tornando-se necessário o uso de misturas em tanque de agrotóxicos. Essa prática é comum não só no Brasil, como em outros países (Guimarães, 2014; Oliveira, 2014; Krause, 2014).

A mistura em tanque é definida como a associação de agrotóxicos e afins no tanque do equipamento aplicador, imediatamente antes da pulverização. Para Guimarães (2014), a mistura em tanque de agrotóxicos ou afins propicia redução de custos, do número de entradas na área, de combustivel e do volume de água, menor compactação do solo, menor tempo de exposição do trabalhador rural ao agrotóxico e melhor manejo e prevenção da resistência de pragas. Mattos et al. (2002) enfatizam a necessidade de realizar estudos relacionados à administração de agrotóxicos em conjunto, considerando-se que estes raramente são aplicados individualmente nas lavouras. As misturas podem apresentar vantagens em comparação à aplicação de um único composto devido ao aumento da eficiência contra os organismos alvo e à diminuição das quantidades aplicadas e dos custos.

A mistura em tanque pode resultar em efeitos sinérgico, aditivo ou antagônico em relação ao efeito de cada produto fitossanitário utilizado isoladamente. A importância de determinar as concentrações de misturas de agrotóxicos que causam efeitos prejudiciais em espécies não alvo, assim como a necessidade de realizar estudos experimentais relacionados à exposição conjunta de agrotóxicos e aprimorar a sua metodologia, foi abordada por Castro (2009). Tais metodologias poderiam predizer as condições sob as quais as interações têm probabilidade de ocorrer. A compreensão do conceito de toxicidade de misturas e o desenvolvimento da capacidade para calcular quantitativamente a toxicidade delas podem ser ferramentas úteis para determinar as vantagens e desvantagens do uso de misturas. Há, portanto, a necessidade de construir uma agricultura que considere os aspectos sociais, econômicos e ambientais (Castro, 2009).

Até meados dos anos de 1980, as indicações técnicas geradas pela indústria e pela academia traziam as recomendações sobre as misturas de produtos. A partir de abril de 1985, todas as recomendações sobre mistura em tanque foram retiradas das instruções de uso por orientação do ofício DIPROF/SDSV 198/85, encaminhado pelo Ministério da Agricultura à ANDEF (Lima, 1997). Ficou então o entendimento de que a mistura em tanque havia sido proibida. Dessa data em diante, inúmeras ações, moções, reuniões, debates em congressos e seminários científicos foram realizados na tentativa de discutir e normatizar o assunto. Com isso, publicou-se a Portaria no 67 em 1995 (Brasil, 1995), que criava a possibilidade de as empresas incluírem nos registros a recomendação das misturas em tanque. Entretanto, novos questionamentos vieram à tona. Deveria a mistura ser permitida apenas com produto comercial ou também com ingrediente ativo? Que consequências poderiam advir das misturas em tanque? Por fim, essa portaria acabou sendo revogada em 2002 pela Instrução Normativa no 46 (Brasil, 2002a). Dessa forma, continuou o questionamento levantado nessas infindáveis discussões: se, de fato, a prática da mistura de tanque era ou não era proibida.

No entendimento da AENDA (AENDA, 2011), a mistura em tanque não é proibida e pode ser praticada pelo agricultor, sob sua responsabilidade. No entanto, é preciso entender que qualquer agrotóxico só pode ser receitado por um profissional legalmente habilitado, e os produtos só poderão ser prescritos com observância das recomendações de uso aprovadas em rótulo e bula, conforme estabelece o Decreto 4.074/02 (Brasil, 2002b). Assim, mesmo que a mistura em tanque não seja proibida, não pode ser prescrita em uma receita agronômica. Com o passar do tempo, as informações de fontes seguras sobre misturas em tanque foram escasseando, até 
se chegar ao panorama atual, com a falta total delas, embora as misturas estejam no cotidiano e façam parte da realidade de campo. Para Ramos \& Araújo (2006), existem informações que chegam ao produtor, as quais têm origem incerta e carecem de confiabilidade. A regulamentação das misturas em tanque é um assunto de interesse de todos os que atuam na área da sanidade vegetal e caracteriza-se como um tema que precisa ser analisado pelos órgãos governamentais no Brasil.

A convivência nas áreas de produção comercial, e com os agentes de assistência técnica e os agricultores, permite a percepção de como os agrotóxicos são utilizados nas propriedades, porém pouco se conhece sobre as informações quantificadas e descritivas do tema. Com o objetivo de registrar as práticas adotadas em relação às misturas em tanque e subsidiar discussões técnicas sobre o tema, foi realizado este estudo, baseado em questionário enviado e aplicado aos profissionais que lidam cotidianamente com tratamentos fitossanitários em diferentes regiões produtoras do Brasil.

\section{MATERIAL E MÉTODOS}

Foi elaborada uma pesquisa com questionário contendo perguntas sobre misturas em tanque de agrotóxicos, como: frequência e época de uso, produtos, doses, vantagens e desvantagens, área cultivada, volumes de água utilizados na calda, misturas com glyphosate, e outras informações sobre o assunto. Parte das perguntas permitia a escolha objetiva de uma resposta, parte delas permitia a indicação de múltiplas respostas, e outras necessitavam de respostas descritivas. A pesquisa foi disponibilizada na internet e enviada para o cadastro de e-mails de instituições e profissionais envolvidos com a cadeia produtiva agrícola. Parceiros institucionais também participaram, reenviando a pesquisa aos seus contatos cadastrados, envolvendo produtores, assistentes técnicos de cooperativas, assistentes técnicos particulares (consultores) e assistentes técnicos da área governamental. Foram abrangidas diferentes culturas e sistemas de produção em várias regiões do Brasil. Foram organizados os percentuais para cada resposta objetiva e de múltipla escolha, e as descritivas foram agrupadas de acordo com as semelhanças dos temas abordados. O sistema adotado não permitiu a identificação dos profissionais e instituições que se dispuseram a responder o questionário.

\section{RESULTADOS E DISCUSSÃO}

Foram recebidas 500 respostas advindas de 17 Estados do Brasil, representando uma diversificação de culturas e sistemas de produção. Os resultados descritos a seguir expõem uma visão da realidade de campo, permitindo quantificar a frequência de uso das misturas em tanque e gerar informações relacionadas a essa prática.

\section{Caracterização dos entrevistados e das áreas}

Quatro categorias de profissionais participaram da pesquisa, com percentuais aproximados entre si. A assistência técnica privada (consultores) representou 19\% das respostas, 23\% foram da assistência técnica ligada ao governo (empresas de assistência técnica e extensão rural), 35\%, da assistência técnica ligada às cooperativas, e $23 \%$, de produtores rurais autônomos (Figura 1).

Observa-se que a que a soma dos percentuais de participações dos técnicos dos diferentes segmentos totalizou $77 \%$. Isso significa que há um fator de multiplicação envolvido nas respostas, uma vez que um técnico assiste diferentes agricultores e

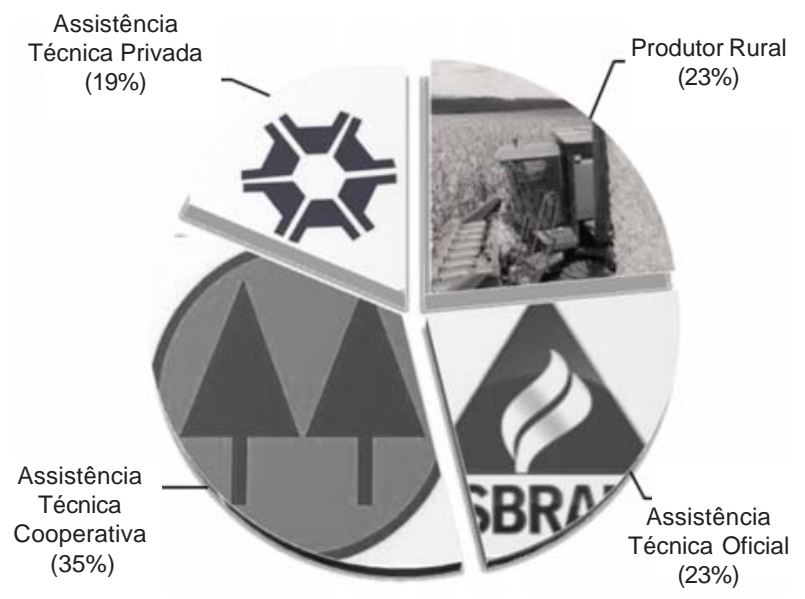

Figura 1 - Distribuição percentual das atividades profissionais dos participantes da pesquisa.

Planta Daninha, Viçosa-MG, v. 33, n. 1, p. 83-92, 2015 
propriedades. É compreensível o interesse desse segmento, visto que a falta de regulamentação das misturas em tanque e a impossibilidade de poder prescrever receitas contendo as misturas afetam todos, mas em particular esses profissionais, pois cabem a eles as recomendações para a solução dos problemas fitossanitários.

Quanto à distribuição das respostas por Estado, o Paraná teve a maior participação, com a metade das respostas enviadas $(50,2 \%)$, seguido do Rio Grande do Sul, com 12,1\%. Somando-se Santa Catarina (2,3\%), os Estados do Sul do Brasil totalizaram $64,6 \%$ de participação. Outros 14 Estados foram responsáveis por $35,4 \%$ das respostas.

Em relação ao tamanho das áreas atendidas ou trabalhadas durante a safra de verão, verificou-se que $11 \%$ dos profissionais se envolvem com no máximo 100 ha; 13\%, entre 100 e 500 ha; $9 \%$, entre 500 e 1.000 ha; e $67 \%$ indicaram estar envolvidos com mais de 1.000 ha. Sobre as culturas plantadas no verão, observa-se predomínio da soja, do milho e do feijão, com 92,1\% das respostas. Embora em percentuais pequenos, são referidas as culturas de café, arroz, algodão, cana-deaçúcar, pastagens, hortaliças e fruteiras. Durante o período da safrinha predomina a cultura do milho $(63,4 \%)$ e a do feijão $(13 \%)$, enquanto no inverno foram citadas as culturas do trigo (42\%), da aveia (23\%) e do feijão (7\%). Os percentuais restantes mostram um número bem diversificado de culturas cultivadas em cada estação.

\section{Caracterização das aplicações}

Questionados se a aplicação dos agrotóxicos nas propriedades é feita individualmente ou com mais de um produto por aplicação, 97\% responderam que adotam as misturas em tanque (Figura 2). A percepção da realidade de campo indicava que a frequência da prática seria alta, porém não se conhecia a sua magnitude. Perguntados sobre a frequência de uso da mistura em tanque, $47 \%$ responderam que sempre misturam agrotóxicos, enquanto $48 \%$ indicaram que frequentemente adotam a mistura. Apenas $2 \%$ raramente fazem misturas e $3 \%$ não a fazem. Portanto, a mistura em tanque nas propriedades é uma

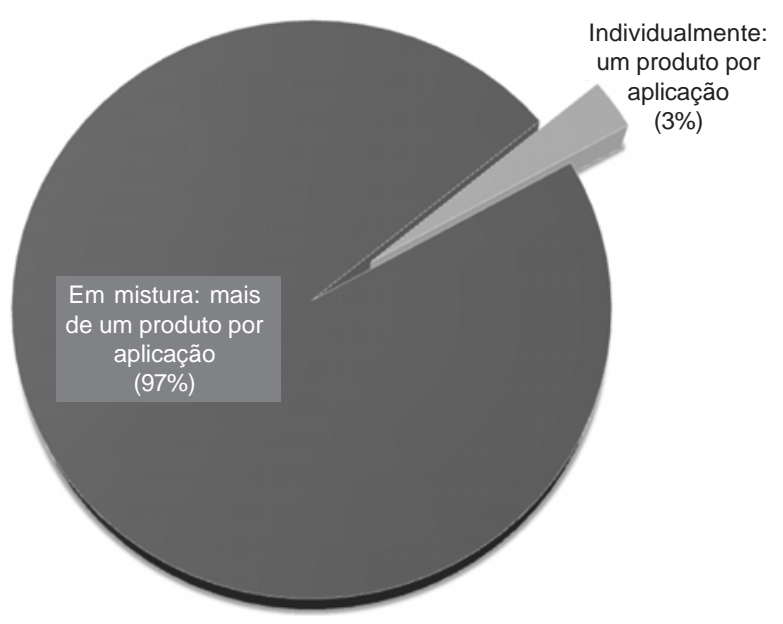

Figura 2 - Como é feita a aplicação de produtos nas propriedades?

prática comum, o que reforça a tese de que esse assunto precisa ser rediscutido pelos componentes das cadeias produtiva; e, em especial, pelos órgãos governamentais.

Segundo Oliveira (2014), a mistura em tanque é uma prática internacional respaldada por resultados de pesquisas científicas. No Brasil, pesquisas científicas publicadas nessa área envolvem misturas de compostos. Rodrigues \& Vitoria Filho (1981) estudaram a mistura de bentazon e paraquat em cultivares de feijão e plantas daninhas. O paraquat é um produto de contato não seletivo, e seu efeito tóxico à cultura foi menor quando em mistura com bentazon, comparativamente ao seu uso isolado. O mesmo aconteceu com Digitaria insularis e Cassia tora. Todavia, a intoxicação das plantas aumentou em Sida glaziovii e Portulaca oleracea. Gazziero et al. (2003) observaram que plantas de Bidens subalternans resistentes aos herbicidas inibidores da acetolactato sintase (ALS) foram controladas quando os agroquímicos com esse mecanismo de ação foram combinados com inibidores da protoporfirinogênio oxidase (PROTOX).

As misturas de herbicidas representam importante ferramenta no controle de plantas daninhas resistentes. A utilização de misturas não ocorre apenas durante o ciclo vegetativo das culturas. Nas áreas cultivadas com grãos, as aplicações no manejo das plantas daninhas na entressafra costumam ser feitas com pelo 
menos dois herbicidas, simultaneamente. A combinação de produtos de diferentes mecanismos de ação pode solucionar os problemas com as espécies resistentes ao glyphosate, como Conyza spp., Digitaria insularis e Lollium muliflorum, em campo (Vargas et al., 2013).

No tocante relação ao número de produtos que costumam ser misturados na mesma operação, observou-se que em $16,1 \%$ dos casos são aplicados apenas dois produtos; em 40,7\% das vezes se utilizam três produtos; em $26,4 \%$ são usados quatro produtos; cinco produtos são misturados em 11,8\% das aplicações; e em 5\% das respostas ocorre a mistura de seis ou mais produtos aplicados concomitantemente (Figura 3). É importante mencionar que nessas respostas o adjuvante recomendado para determinados produtos não foi considerado como um produto. Essa pergunta também deve ser analisada com muita atenção, pois 95\% das misturas contemplam o uso de dois a cinco produtos em um só tanque. A percepção sobre misturas também indicava o uso de vários produtos ao mesmo tempo, o que foi confirmado nesse levantamento.

Thiesen \& Ruedell (2004) e Mariano \& Ostrowski (2007) destacam a importância de

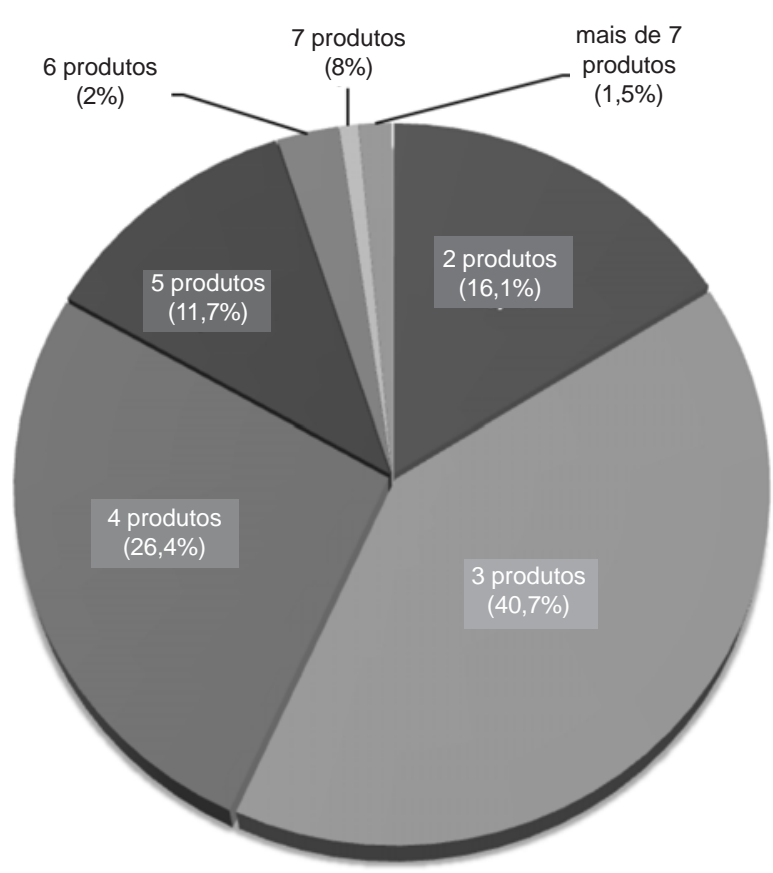

Figura 3 - Quantos produtos (inseticida, fungicida, herbicida, adubo foliar, etc.) costumam ser misturados na mesma operação? conhecer qual a sequência na adição dos produtos quando se faz a mistura em tanque ou a pré-mistura, como uma forma de evitar incompatibilidades. Quando perguntados sobre a maneira como é realizada a mistura, verificou-se que em $69 \%$ das vezes ela é feita diretamente no tanque de pulverização, e somente $31 \%$ são pré-misturados antes de serem colocados no pulverizador. A prémistura é recomendada para verificar a existência de reações indesejadas. As combinações mais frequentes envolvem inseticidas com fungicidas em $31 \%$ das misturas, inseticida com fungicida e herbicida em $16 \%$, e $27 \%$ contemplam, além desses três produtos, mais adubos foliares. Um considerável percentual (19\%) relata que, além dessas classes de produtos, também são adicionados outros produtos no tanque de pulverização. Na sequência, perguntou-se sobre quais eram esses produtos e foram estimulados relatos descritivos, com detalhes adicionais.

Vários tipos de informações foram fornecidas sobre como são as combinações dos produtos e classe de produtos. São utilizados dois ou três tipos de herbicidas na dessecação, dois ou três tipos de herbicidas e fungicidas em pós-emergência da cultura, adjuvantes, redutores de $\mathrm{pH}$, surfatantes, antiespumante, antideriva, óleos minerais e vegetais, piretroides e inseticidas fisiológicos. Há relatos descritivos de misturas de até oito produtos sem prejuízos nos resultados. Esse item reforça a tese de que, ao se fazer a aplicação de um determinado produto, aproveita-se para aplicar outros produtos da época, evitando-se a reentrada na área. Atualmente, quase a totalidade das áreas cultiva a soja RR (soja tolerante ao glyphosate). Observa-se que esse herbicida é aplicado em pós-emergência da cultura em misturas em tanque com inseticidas e fungicidas em $72 \%$ das vezes. Em $14 \%$ dos casos, o glyphosate é aplicado com outros herbicidas, e apenas em $14 \%$ das vezes se utiliza esse produto de forma isolada (Figura 4).

\section{A água nas aplicações}

A água serve como veículo na distribuição dos agrotóxicos. A quantidade utilizada pode 


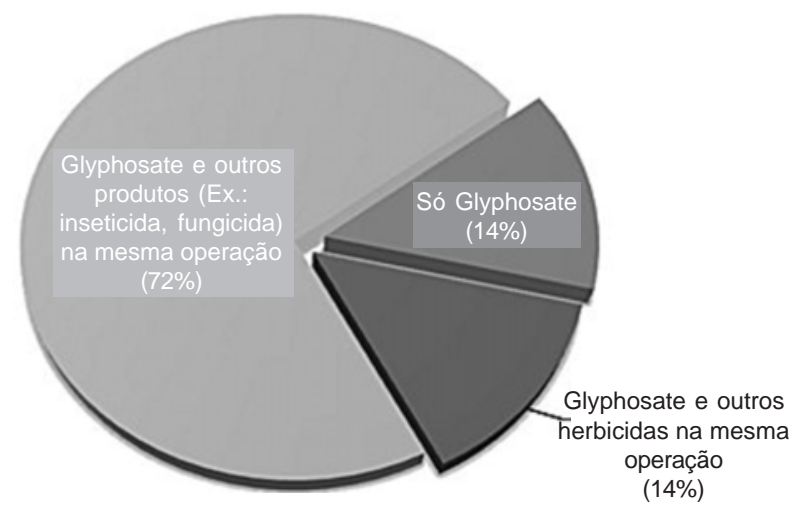

Figura 4 - Como é feito o controle de plantas daninhas na pósemergência da soja RR?

variar com o produto e o equipamento. Produtos com ação de contato geralmente necessitam de maior cobertura do alvo que os sistêmicos, por isso precisam de maior volume de calda. Com relação à pesquisa, nas aplicações terrestres e aéreas, os entrevistados responderam que o volume de água utilizado por hectare tem sido de 100 a $180 \mathrm{~L} \mathrm{ha}^{-1}$ na maioria das aplicações terrestres (55\%).

Pulverizações com mais de $180 \mathrm{~L} \mathrm{ha}^{-1}$ representam $26 \%$ dos casos, e abaixo de $100 \mathrm{~L} \mathrm{ha}^{-1}$ compreende $18 \%$. A água é fundamental nas aplicações de agrotóxicos, mas deve ser usada com racionalidade. Nessa ótica, as misturas em tanque ajudam na preservação desse recurso natural. Nas aplicações aéreas ocorre importante redução no consumo de água, sendo na maioria dos casos (42\%) utilizados de 10 a $20 \mathrm{~L} \mathrm{ha}^{-1}$. Segundo Theisen \& Ruedell (2004), é possivel trabalhar com volumes de calda menores dos que os tradicionais (200 a $400 \mathrm{~L} \mathrm{ha}^{-1}$ de água), e, embora alguns herbicidas de solo e outros defensivos contenham em seus rótulos e bulas a indicação para aplicação com até $300 \mathrm{~L} \mathrm{ha}^{-1}$ de calda, a utilização de menores volumes de calda não irá prejudicar o desempenho desses produtos.

\section{Beneficios e desvantagens}

No questionário aplicado constavam questões que objetivavam captar a visão dos entrevistados quanto às vantagens e desvantagens da utilização de agrotóxicos em misturas. Em relação às vantagens, 30\% das respostas justificaram a adoção dessa prática pela economia de tempo, de mão de obra e de óleo diesel. A agilidade nas operações representou $26 \%$, a facilidade de manejo da cultura, $24 \%$, enquanto $15 \%$ justificaram o uso em virtude da diminuição da compactação do solo. Outros pontos abordados referem-se a aumento do espectro de ação das misturas, manejo da resistência, aplicação no momento adequado e um possível efeito sinérgico.

Em relação às desvantagens, $44 \%$ dos entrevistados apontaram a falta de regulamentação como um problema, e 32\% manifestaram preocupação com os riscos à saúde e ao ambiente. Entre as desvantagens aparecem ainda questões relacionadas a pouca informação disponivel, intoxicação da cultura, incompatibilidade química e redução da eficiência (antagonismo). Para alguns (6\%), ocorre maior desgaste dos equipamentos, e cerca de $7 \%$ afirmam desconhecer as desvantagens.

\section{Problemas com as misturas}

Na literatura, é possivel observar diferentes resultados sobre compatibilidades e vantagens das misturas de diferentes produtos. A qualidade química da água é outro fator que deve ser analisado, em razão da quantidade de outros íons que a compõem e que não são constituintes da dureza. Por exemplo, íons como $\mathrm{Fe}^{+3}$ e $\mathrm{Al}^{+3}$ podem reagir com o agrotóxico, reduzindo sua eficácia (Petter et al., 2013; Pazini et al., 2013; Ramos $\&$ Araujo, 2006). Maciel et al. (2010) estudaram a tensão superficial estática, o pH e a produção da espuma de misturas em tanque de formulações de glyphosate + chlorimuronethyl, associadas ou não com adjuvantes. Os resultados indicaram que as misturas em tanque desses herbicidas não interferiram nas características físico-químicas de tensão superficial estática e $\mathrm{pH}$ das soluções, apesar de haver risco de maior quantidade e persistência de espuma. Esses autores indicam também que todos os adjuvantes promoveram pequenas variações dos niveis médios de pH das soluções e, em alguns casos, reduziram a tensão superficial e a quantidade e persistência da espuma.

Consultados sobre o conhecimento de problemas decorrentes da mistura em tanque, 
$71 \%$ dos participantes da pesquisa responderam haver problemas, enquanto $29 \%$ responderam negativamente. A Figura 5 apresenta a distribuição percentual dos problemas com as misturas em tanque no que se refere a dificuldade de dissolver os produtos misturados, aumento da fitotoxicidade, excesso de formação de espuma, entupimento de bicos e decantação (precipitação) de produtos no tanque. Todavia, na maioria das vezes esses problemas ocorrem de forma ocasional, ou podem não ocorrer.

Dessa forma, antes de qualquer mistura, é preciso saber se há ou não a possibilidade de superveniência de problemas. Não se podem admitir aplicações que aumentem a fitotoxicidade, promovam o entupimento de bicos e gerem a decantação de produtos ou redução da solubilidade na água.

Devido à amplitude de problemas que podem ocorrer com o uso de misturas, foi solicitado aos participantes que apresentassem de forma descritiva os problemas que verificaram com o uso de misturas, as inseguranças quanto ao seu uso e outras considerações.

As principais manifestações foram:

1. Possibilidade de incompatibilidades física e química, efeitos sinérgicos ou antagônicos (para alguns produtos, é considerada obrigatória a pré-mistura).

2. Floculação, decantação e formação de grânulos ou pastas, aderência de produtos nas paredes, filtros e mangueiras do pulverizador.

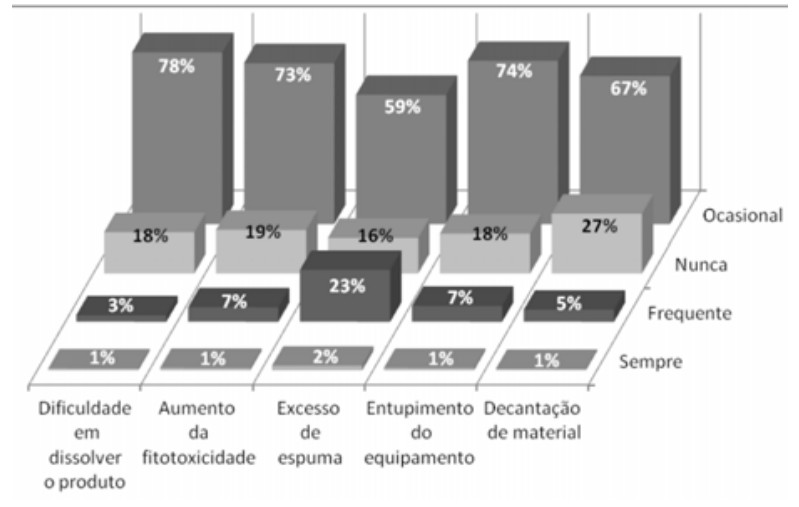

Figura 5 - Frequência de ocorrência de problemas quando da utilização de misturas em tanque.
3. A qualidade das misturas depende da dureza da água, dos produtos utilizados, dos equipamentos e do modo de preparo da calda no tanque. Foram citados exemplos de problemas com o uso de manganês, enxofre, molibdato de sódio e sulfato de cobalto, fertilizantes foliares em geral, formulação WG, pó molhável e suspensão concentrada, assim como sobre a calda deixada no tanque de um dia para outro.

4. Dúvidas sobre o efeito do $\mathrm{pH}$ da água na redução ou aumento de eficiência dos produtos. Foram citados vários exemplos de produtos que alteram o $\mathrm{pH}$ da calda e que certas misturas podem causar redução da eficiência.

5. A sequência de colocação dos produtos no tanque aparenta interferir nas propriedades dos produtos fitossanitários.

6. Deficiência de informações com credibilidade sobre o uso de misturas em tanque. Foi referido o autoaprendizado, de maneira que os aplicadores mais experientes evitam o surgimento de determinados problemas.

7. Na superveniência de problemas com as misturas, não é possível reclamar com o fabricante.

8. Ausência de orientação de procedimento em caso de intoxicação.

9. Preocupação com a possibilidade de contaminação do ambiente.

10. Aplicações individualizadas de produtos (sem as misturas) inviabilizam os cultivos.

Ainda nas respostas descritivas, foram citados exemplos de incompatibilidade envolvendo as diferentes classes de agrotóxicos, assim como foi observado que raríssimas vezes acontecem problemas com as misturas em tanque, desde que se pesquise antes a possibilidade de alguma reação, ou quando há orientação correta.

Petter et al. (2013) estudaram a compatibilidade das misturas de inseticidas com fungicidas no tanque de pulverização. Esses autores verificaram que o uso de redutores de $\mathrm{pH}$ pode proporcionar maior estabilidade química na calda ou redução da incompatibilidade em alguns casos. Petter et al. (2012) relataram incompatibilidades de 
algumas misturas entre herbicidas e inseticidas, variáveis em função dos produtos utilizados e suas formulações. Foi observado que os ácidos pirolenhoso e bórico são alternativas para redução do pH. Pazini et al. (2013) encontraram diferentes graus de estabilidade das caldas ao estudar a mistura entre herbicidas e inseticidas e entre fungicidas e inseticidas. Ramos \& Araújo (2006) destacaram a importância do preparo da calda na eficácia de agrotóxicos e a necessidade de informações e publicações idôneas para a segurança do aplicador e do ambiente.

\section{Doses utilizadas}

Uma dúvida constante sobre a prática da mistura em tanque refere-se ao fato de as doses constantes do rótulo de produtos da mesma classe serem utilizadas ou alteradas. A Figura 6 mostra que em 59\% dos casos é mantida a dose máxima (dose cheia) constante no rótulo de cada um dos produtos aplicados em mistura, e o inverso ocorre em $16 \%$ dos casos, ou seja, há redução de dose em todos os produtos.

Em 25\% das respostas observa-se que a redução é apenas de um produto. Não fica claro quais os critérios da tomada de decisão sobre a dose utilizada e quais problemas estão associados a cada um dos procedimentos. Possivelmente, as experiências com tentativa e erro ajudam a definir a dose mais adequada

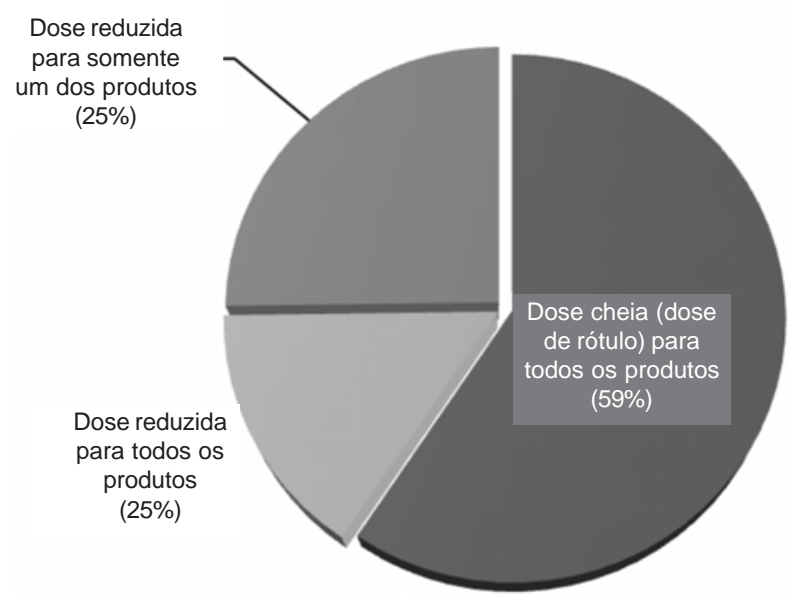

Figura 6 - Porcentagem de dose utilizada por ocasião da mistura de produtos com a mesma finalidade (ex.: dois ou mais herbicidas, dois ou mais fungicidas). e segura. Krause (2014) enfatiza que as doses devem ser ajustadas a cada situação requerida em função do problema encontrado no campo e que as misturas representam uma forma de poder ampliar o espectro de controle. Além disso, o autor alerta para a falta de lançamento de novos herbicidas com diferentes mecanismos de ação.

\section{Informações técnicas}

Quando os entrevistados foram questionados no tocante às informações técnicas relacionadas à utilização das misturas em tanque, $72 \%$ das respostas indicaram que não são suficientes ou que as desconhecem (Figura 7). Esse é outro ponto fundamental para reflexão: Por que uma prática tão comum tem tão pouca informação disponível? O exposto confirma a necessidade de rediscutir esse assunto e gerar e disponibilizar informações para que seu uso não envolva riscos desnecessários.

Segundo Thiesen \& Ruedell (2004), a literatura internacional mostra que nos países onde as misturas são permitidas e regulamentadas os riscos diminuem, pois precauções são adotadas. Esses autores relacionam vários exemplos de incompatibilidade com misturas de diferentes herbicidas entre si, herbicidas com inseticidas e fertilizantes com herbicidas. A compilação de dados feita por técnicos da COAMO (Mariano \& Ostrowski, 2007) mostra

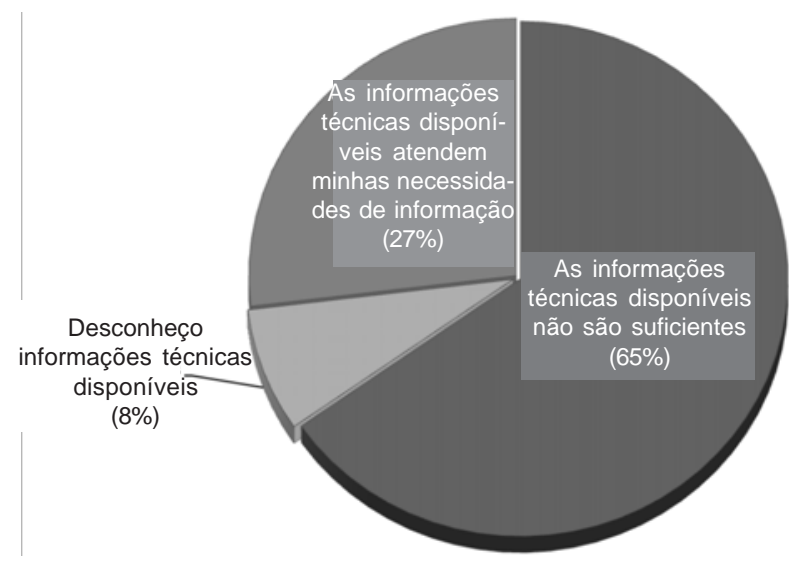

Figura 7 - Opinião dos entrevistados sobre as informações técnicas da mistura em tanque. 
uma série de casos de incompatibilidade ao se proceder a misturas, o que reforça a importância de disponibilizar as informações aos que recomendam e aos que utilizam agrotóxicos.

No que se refere à forma como gostariam de receber as informações, foram sugeridas publicações específicas, informações nas bulas, treinamentos e recomendações técnicas (Figura 8). No total, 99\% dos participantes demonstraram interesse em receber informações sobre misturas em tanque.

Finalmente, os entrevistados responderam sobre a fonte preferencial para receber as informações sobre misturas em tanque. Em $77 \%$ das respostas foi indicada a preferência de que sejam advindas de instituições oficiais de pesquisa/ensino e dos fabricantes (Figura 9). Os demais informaram que gostariam de receber essas informações via assistência técnica. Esse tema é abordado por Ramos \& Araújo (2006), que afirmaram ser comum a existência de tabelas sobre "pH ideal" sem que se saiba quem as elaborou. No passado, encontravam-se tabelas sobre misturas de herbicidas para uso na soja convencional, mas sem a indicação da fonte. Ou seja, a falta de regulamentação pode levar à clandestinidade da informação ou até mesmo à falta dela. Com o passar dos anos, aumentou o número de produtos no mercado e as dúvidas sobre como utilizá-los em misturas em tanque, ao passo que, ao mesmo tempo, as informações disponibilizadas eram reduzidas.

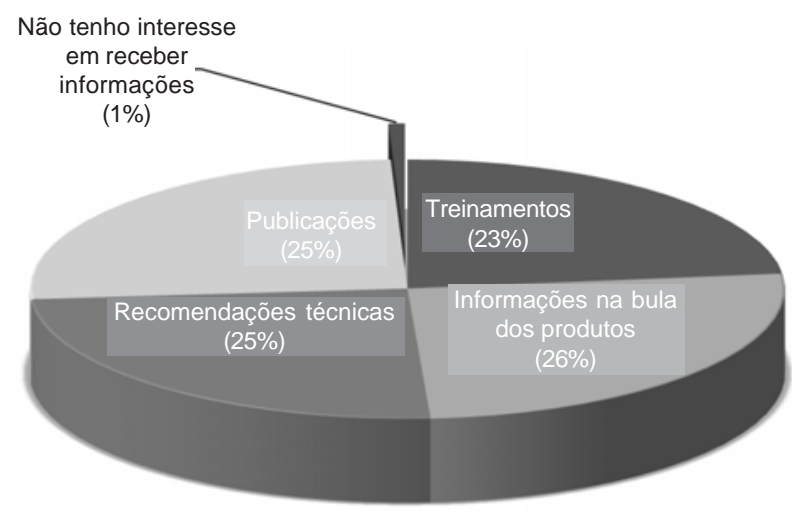

Figura 8 - De que maneira gostaria de receber informações sobre misturas em tanque?

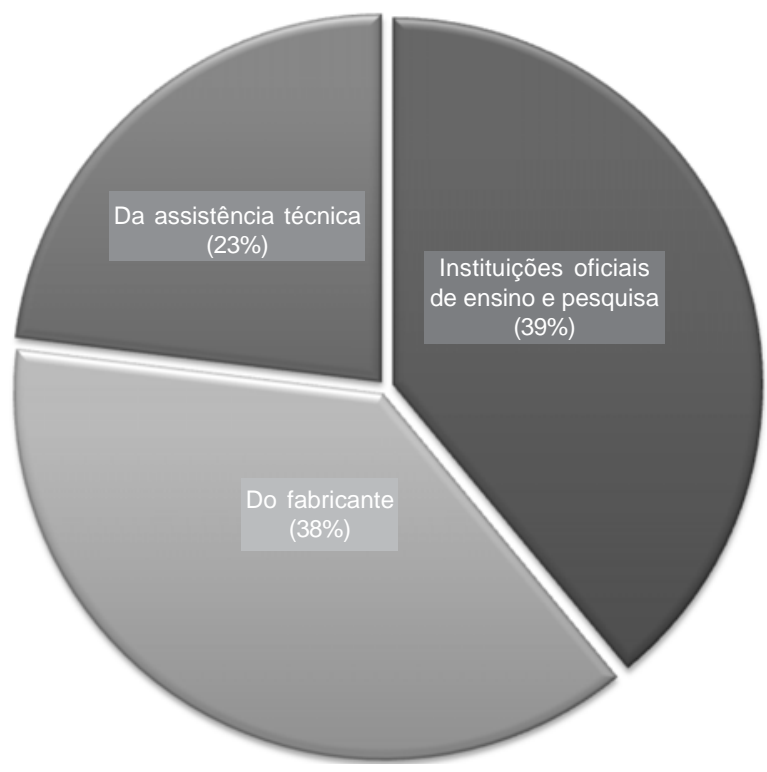

Figura 9 - Qual sua fonte preferencial para receber informações sobre mistura em tanque?

Portanto, conclui-se que as misturas em tanque são práticas usuais no campo e adotadas por $97 \%$ dos entrevistados neste estudo. A forma como os agrotóxicos estão sendo misturados atualmente pode representar vantagens e desvantagens nas pulverizações agrícolas. As informações sobre misturas em tanque são insuficientes ou desconhecidas e faltam pesquisas e regulamentação. Assim, pode-se afirmar que se trata de um assunto para ser discutido com urgência com os órgãos governamentais competentes.

\section{LITERATURA CITADA}

\section{ASSOCIAÇÃO BRASILEIRA DOS DEFENSIVOS GENÉRICOS - AENDA. Mistura em tanque. Caderno AENDA, n. 1, p. 1-11, 2011.}

BRASIL. Ministério da Agricultura, Pecuária e Abastecimento. Portaria n. 67 de 30 de maio de 1995. Regulamenta o uso das misturas de agrotóxicos em tanque. Diário Oficial da União, Brasília, DF, 1995.

BRASIL. Ministério da Agricultura, Pecuária e Abastecimento. Instrução Normativa n. 46, de 24 de julho de 2002. Determina às empresas titulares de registros de agrotóxicos a retirada das indicações de misturas em tanque dos rótulos e bulas de seus agrotóxicos. Diário Oficial da União, Brasília, DF, 2002a. 
BRASIL. Ministério da Agricultura, Pecuária e

Abastecimento. Decreto 4074 que regulamenta a Lei 7802 de 11 de julho de 1989 que dispõe sobre agrotóxicos, seus componentes e afins e de outras providencias. Diário Oficial da União, Brasília, DF, 2002b.

CASTRO, V. L. S. S. Uso de misturas de agrotóxicos na agricultura e suas implicações toxicológicas na saúde. J. Braz. Soc. Ecotoxicol., v. 4, n. 1-3, p. 87-94, 2009.

GAZZIERO, D. L. P.; PRETE, C. E. C.; SUMIYA, M. Manejo de Bidens subalternans resistente aos herbicidas inibidores da acetolactato sintase. Planta Daninha, v. 21, n. 2, p. 283-291, 2003.

GUIMARÃES, G. L. Principais fatores comerciais condicionantes da disponibilidade de produtos isolados e em misturas. In: CONGRESSO BRASILEIRO DA CIÊNCIA DAS PLANTAS DANINHAS, 29., 2014, Gramado. Palestra... Gramado: 2014. CD ROM.

OLIVEIRA, T. Mistura em tanque, aspectos legais. In: CONGRESSO BRASILEIRO DA CIÊNCIA DAS PLANTAS DANINHAS, 29., 2014, Gramado. Palestra... Gramado: 2014. CD ROM.

KRAUSE, N. D. Necessidades tecnológicas relacionadas a novos ingredientes ativos, formulações e da prática da realização de misturas de agrotóxicos. In: CONGRESSO BRASILEIRO DA CIÊNCIA DAS PLANTAS DANINHAS, 29., 2014, Gramado. Palestra... Gramado: 2014. CD ROM.

LIMA, L. C. F. Produtos fitossanitários: misturas em tanque. Cascavel: Ocepar/Coodetec/Associação Nacional de Defesa Vegetal, 1997. 13 p. (Relatório Técnico)

MACIEL, C. D. G. et al. Tensão superficial estática de misturas em tanque de glyphosate + chlorimuron-ethyl isoladas ou associadas com adjuvantes. Planta Daninha, v. 28, n. 3, p. 673-675, 2010.
MARIANO, J.; OSTROWISKI, A. C. Adição de produtos fitossanitários à calda de pulverização. Coamo, 2007.

MATTOS, M. et al. Avaliação de estratégias com agroquímicos no controle de Bemisia argentifolii Bellows \& Perring (Hemiptera: Aleyrodidae) em tomate. Pestic.: R. Ecotoxicol. Meio Amb., v. 12, n. 1, p. 131-144, 2002.

PAZINI, J. B. et al. Compatibilidade física de misturas de agrotóxicos. Disponível em: <http://www.cbai2013.com.br/ docs/trab-7645-291.pdf>. Acesso em: 3 nov. 2014.

PETTER, F. A. et al. Incompatibilidade física de misturas entre inseticidas e fungicidas. Comunicata Sci., v. 4, n. 2, p. 129-138, 2013.

PETTER, F. A. et al. Incompatibilidade fisica de misturas entre herbicidas e fungicidas. Planta Daninha, v. 30, n. 2, p. 449-457. 2012

RAMOS, H. H.; ARAÚJO, D. Preparo da calda e sua interferência na eficácia de agrotóxicos. Artigo em Hypertexto. 2006. Disponível em: <http://www.infobibos. com/Artigos/2006_3/V2/index.htm>. Acesso em: 3 nov. 2014.

RODRIGUES, B. N.; VICTORIA FILHO, R. Efeitos de misturas de bentazon e paraquat no controle de plantas daninhas e na cultura do feijão (Phaseolus vulgaris L.). Planta Daninha, v. 4, n. 2, p. 87-91. 1981.

THIESEN, G.; RUEDEL, J. Tecnologia de aplicação de herbicidas: teoria e prática. Cruz Alta: FUNDACEP, 2004. $90 \mathrm{p}$.

VARGAS, L. et al. Histórico, custo e o desafio do manejo no futuro. In: RESTAINO, E. Viabilidad del glyphosate en sistemas productivos sustentables. Estanzuela en Colonia: INIA, 2013. p. 99-110. (Série Técnica, 204) 